\title{
Homocysteine increases the risk of mortality in elderly individuals
}

\author{
Sonia González, José M. Huerta, Serafina Fernández, Ángeles M. Patterson and Cristina Lasheras* \\ Departamento de Biología Funcional, Área de Fisiología, Facultad de Medicina, Universidad de Oviedo, Julián Clavería s/n, \\ 33006, Oviedo, Spain
}

(Received 10 July 2006 - Revised 15 December 2006 - Accepted 18 December 2006)

\begin{abstract}
Although total plasma homocysteine (tHcy) has been extensively studied as a risk factor of CVD, longitudinal evidence on its association with mortality is scarce, especially among the elderly. The study cohort consisted of 215 subjects (eighty-eight male and 127 female), aged 60 years or older, recruited in fourteen elderly care institutions from Asturias (Spain). All participants were free of major chronic pathology and took no vitamin and/or mineral supplements. Baseline determinations included tHcy in plasma and folate, vitamin $\mathrm{B}_{12}$ and Se in serum. Survival analyses were performed by quintiles of these factors after 6 years (mean follow-up time 4.3 years) by means of Cox regression models. During follow-up time sixty participants died. tHcy above $16.7 \mu \mathrm{mol} / \mathrm{l}$ was associated with an increased risk of mortality in the sample (relative risk 2.30 $(95 \%$ CI 1.02, 5.17)). Among the nutritional determinants of tHcy evaluated, folate and Se were not predictive of death risk of the cohort, while vitamin $B_{12}$ showed inconsistent results. Nevertheless, mortality was significantly lower at higher serum Se levels (upper quintile), but this effect was restricted to women. Higher tHcy in both sexes and lower serum Se in women were found to be independently associated with an increased risk of death in elderly subjects.
\end{abstract}

Homocysteine: Vitamins: Selenium: Mortality: Elderly

Homocysteine is a sulfur-containing amino acid playing a key role in methionine metabolism (Finkelstein, 1990) that has been described to be a useful biological marker of disease. In the last two decades, many retrospective and cross-sectional studies have consistently linked premature vascular disorders and CVD with higher total plasma homocysteine (tHcy) levels (Graham et al. 1997; Hankey \& Eikelboom, 1999; Homocysteine Studies Collaboration, 2002). Prospective investigations have also found that cardiovascular risk rises with increasing tHcy in a dose-dependent manner (Boushey et al. 1995; Perry et al. 1995), while subjects with lower tHcy levels also show reduced risk of stroke and IHD (Homocysteine Studies Collaboration, 2002). Nevertheless, recent randomised clinical trials designed to lower tHcy concentrations have proven ineffective in preventing cardiovascular events (Bonaa et al. 2006; Lonn et al. 2006), so that controversy still exists. In addition to its role on cardiovascular morbidity, recent research has suggested that tHcy might also be implicated in several other age-related pathologies, such as Alzheimer's disease, dementia (Clarke et al. 1998; Morris, 2003) and osteoporosis (Verhoef \& de Groot, 2005), although the mechanisms underlying these associations have not yet been elucidated.

In agreement with its well-documented association with chronic disease, studies carried out to analyse whether plasma homocysteine would be predictive of mortality in human subjects show consistent results. Several authors have found supporting evidence for this association in patient populations with renal failure (Buccianti et al. 2004), CVD (Nygard et al. 1997;
Anderson et al. 2000; Omland et al. 2000; Rossi et al. 2006) and diabetes (Stehouwer et al. 1999). It should be pointed out, nevertheless, that all these subjects in whom tHcy has been found to predict fatal outcomes were already at higher risk of overall mortality because of their underlying pathological conditions. Although some authors have reported an association of tHcy with mortality in non-risk populations (Bostom et al. 1999; Kark et al. 1999; Vollset et al. 2001), at least one study has failed to find tHcy associated with cardiovascular mortality (de Bree et al. 2003). Still, epidemiological data on this topic are scarce, especially among the elderly.

Hyperhomocysteinaemia is determined by genetic, environmental and nutritional factors (Selhub, 1999; Jacques et al. 2001; Saw et al. 2001). Folate, vitamin $\mathrm{B}_{12}$, vitamin $\mathrm{B}_{6}$ and riboflavin are the most studied nutritional determinants of plasma tHcy concentrations (Selhub et al. 1993; Brouwer et al. 2000; Jacques et al. 2002); however, a recent study carried out by our group has also found Se to be a strong and independent determinant of the levels of this amino acid (González et al. 2004). The significant association of all these factors with plasma homocysteine concentrations allows us to conceive a potential role for them in preventing tHcy-related pathologies and, eventually, mortality.

The present longitudinal study has been conducted to analyse the prospective association of homocysteine, and several nutrition-related factors, on survival time in elderly subjects from the North of Spain who were followed up for a maximum of 6 years.

\footnotetext{
Abbreviations: THcy, total plasma homocysteine.

* Corresponding author: Dr Cristina Lasheras, fax +34 98 5103534, email lasheras@uniovi.es
} 


\section{Subjects and methods}

Study sample, setting and recruitment

A total sample of 304 subjects (age 60 years old and over) was recruited in Asturias (Northern Spain) between 1999 and 2002, in fourteen public and private care institutions for elderly individuals. The recruitment of the sample comprised two phases. Phase 1 took place between 1999 and 2000 and included 184 elderly subjects from seven elderly care institutions. In phase 2 (year 2002), the previous sample was enlarged with 120 new participants from seven other different institutions.

A medical history of each subject was obtained before enrolment. Subjects were required to be mentally and physically able to take part in the study. On this basis, elderly residents with a previous history of cancer, mental impairment or CVD were not included, and neither were those confined to a wheelchair or suffering from a terminal disease. A total of eighty-nine subjects were excluded from the analyses due to missing values in biochemical parameters ( $n$ 38), regular consumption of vitamin and/or mineral supplements $(n 4)$ or following a special diet $(n 47)$. The final sample comprised 215 subjects, eighty-eight men and 127 women, with a mean age of 73.4 (SD 7.3) and 76.3 (SD 5.7) years, respectively.

The study design was approved by the Committee on Ethical Research of the Asturias Central University Hospital. All participants were informed of the objectives and methodology of the study and gave written consent.

\section{Data collection}

The longitudinal analysis presented in the present paper is part of a broader epidemiological study on diet, biological markers of disease and mortality. As part of the dietary approach, variables concerning energy, and macro- and micronutrient intake were recorded, by trained dietitians, by means of a FFQ specific for each of the fourteen institutions. Methodological details in regard to dietary assessment have been presented elsewhere (Lasheras et al. 2003).

During the personal interview information was also collected on potential confounders such as smoking habit (yes, no), and cognitive status, measured by means of the Lobo test, an adaptation of the Mini Mental State Examination for the Spanish population (Lobo et al. 2005). A medical history was obtained for each participant, and consumption of drugs was registered.

Height (in $\mathrm{m}$ ) of the participants was measured using a stadiometer exact to $1 \mathrm{~mm}$ (Año-Sayol, Barcelona, Spain), with subjects barefoot and positioned in the Frankfort plane. Weight (in $\mathrm{kg}$ ) was registered to the nearest $500 \mathrm{~g}$ with a precision scale (Seca, Hamburg, Germany). BMI of the participants was then calculated as weight divided by height squared $\left(\mathrm{kg} / \mathrm{m}^{2}\right)$.

\section{Blood sample pre-treatment and biochemical analyses}

A total of $30 \mathrm{ml}$ of whole blood were drawn from each participant by venepuncture after a $12 \mathrm{~h}$ fast, and collected in separated tubes for serum and plasma. Samples were kept cold in the dark until processed in the laboratory. To obtain plasma samples, heparin-treated tubes were centrifuged at $1000 \mathrm{~g}$ for
$15 \mathrm{~min}$ at room temperature within the following $2-4 \mathrm{~h}$ after the collection. Blood collected into non-heparinised tubes was allowed to clot in the dark at room temperature for $4 \mathrm{~h}$ before centrifugation, and serum removed. Plasma and serum samples of $500 \mu \mathrm{l}$ were stored frozen at $-70^{\circ} \mathrm{C}$ until analyses were performed.

tHcy was determined using reverse-phase HPLC with fluorimetric detection (Araki \& Sako, 1987) on Bio-Rad equipment (Bio-Rad, Richmond, CA, USA). To assure the stability of the analytical procedure, cysteine and cysteineglycine (two aminothiols) were measured together with homocysteine in the same sample and their concentrations (absolute and relative to homocysteine) were checked to be within the reference range. $\mathrm{CV}$ for tHcy determination was $8 \%$. Serum folate and vitamin $\mathrm{B}_{12}$ concentrations were determined using a competitive-binding immunoenzymic assay on an Access ${ }^{\circledR}$ automated immunoassay analyser from Beckman (Chaska, MN, USA). Imprecision (as the CV) was $15 \%$ for folate and $7 \%$ for vitamin $B_{12}$. Se was analysed in serum by graphite-furnace flame atomic absorption spectrometry (Jacobson \& Lockitch, 1988). Seronorm Trace Elements Serum standard (SERO AS, Billingstad, Norway) was used as quality control. $\mathrm{CV}$ for Se determination was $10 \%$. Serum creatinine was measured in a Hitachi 737 analyser (Boehringer Mannheim Corp., Indianapolis, IN, USA) by the modified kinetic Jaffé reaction (Kasiske \& Keane, 1996).

Biochemical analyses were performed at the Laboratory of Clinical Analysis of Asturias Central Hospital (Oviedo, Spain).

\section{Statistical analyses}

Goodness of fit to normal distribution of continuous variables was analysed with the Kolmogorov-Smirnov test. Student's $t$ tests were used to check for differences by vital status of the study sample. When distributions were skewed, a log-transformation was applied and differences analysed by means of the non-parametrical Mann-Whitney $U$ test. For categorical variables, $\chi^{2}$ tests were performed to check for differences in the percentage of subjects across groups.

Cox proportional hazards models were built in order to estimate the relative risk of death by quintiles of predicting variables. The lowest quintile was defined as the reference category in each model. Multivariate adjustment included sex, age, BMI, cognitive test score and smoking habit $(0=$ no; $1=$ yes $)$. Tests for trend across quintiles were performed by entering the categorised variables as continuous.

All analyses were performed with SPSS version 12.0 for Windows (SPSS Inc., Chicago, IL, USA). Differences were considered significant at the $P<0.05$ level.

\section{Follow-up protocol}

Date of entry to the study was set at the date of the personal interview (October 1999 to July 2000 in phase 1 and May 2002 to December 2002 in phase 2). Every following year, the institutions were contacted in order to assess changes in vital status of participants and to register the exact date and probable cause of every death event that had occurred. Extensive efforts were made to contact the participants who had moved out from any institution, requesting the new address 
if possible. When this information was not available, the case was registered as a loss to follow-up, and survival time censored at the date when the participant had left the centre. Less than $4.3 \%$ of subjects ( $n$ 11) were lost to follow-up during the study period. Closing date for survival analyses was considered that of the last contact with each centre (January to February 2006). A total number of sixty death cases (28\%) were registered and, according to information provided, none died of accident or committed suicide. Mean survival time for the whole cohort was $1556 \mathrm{~d}$.

\section{Results}

Baseline characteristics of the study sample are presented in Table 1 for the whole cohort and separately for sex and vital status. Mean age at enrolment was higher in women than in men. The percentage of actual smokers was lower in women, who also showed higher basal serum folate and poorer cognitive performance. Those who died showed significantly higher tHcy and lower serum Se concentrations at enrolment than survivors, but no differences were found for folate or vitamin $\mathrm{B}_{12}$ between both groups. Those subjects who died also had a lower BMI at the time of recruitment (probably a consequence of the different sex ratio between groups and the difference in BMI between men and women).

The results of Cox proportional hazards regression models for categories of studied variables are shown in Table 2. Quintiles of blood homocysteine, folate, vitamin $\mathrm{B}_{12}$ and Se were calculated and introduced as predicting variables in multivariate Cox models, controlling for several potential confounders. A 2.3fold higher risk of death was found for subjects in the upper quintile of tHcy distribution as compared with those in the lowest one (reference category). Serum folate and Se levels were not significantly associated with survival time in the sample. Quintiles of vitamin $B_{12}$ were not associated with overall mortality, but a significant trend in mortality with increasing $\mathrm{B}_{12}$ levels in the fully adjusted model was observed.

\section{Discussion}

The major outcome of the present study is the association between tHcy and Se with risk of overall mortality in a non-risk elderly population. Although multiple evidence supports tHcy as a marker of several pathological conditions, its association with mortality remains insufficiently documented in the general population.

We report a $2 \cdot 3$-fold higher chance of all-cause death in subjects with higher tHcy levels ( $\geq 16.7 \mu \mathrm{mol} / \mathrm{l}$ ), a result which is consistent with the $2 \cdot 2$-fold increase in total mortality risk found by Bostom et al. (1999) for elderly of the Framingham cohort with tHcy above $14.3 \mu \mathrm{mol} / \mathrm{l}$. tHcy has been reported to predict mortality in patients with renal failure or CVD. Its levels increase as a consequence of a diminished renal function; also, tHcy concentrations are known to be elevated for some time after a cardiovascular event, for up to 6 months after a myocardial infarction and for more than 1 year after a stroke (Lindgren et al. 1995; Egerton et al. 1996). Nevertheless, the study of homocysteine in the context of chronic disease might not be an entirely valid approach to establish its potential role as an independent risk factor of mortality. In this sense, it is of importance our reporting of an increased chance of death associated with higher tHcy levels in elderly subjects free of major chronic pathologies. Although limited statistical power in the present study has probably hampered our ability to find a statistically significant graded effect on mortality (see Table 2), it should be noted that the percentage of cases significantly increased across quintiles of tHcy $(P=0 \cdot 027)$. Still more research is necessary to precisely quantify the magnitude of the contribution of homocysteine to risk of death in the general population by strata of relevant biological, social and pathological variables.

Survival analyses were also performed for major nutritional determinants of tHcy. Folate and vitamin $B_{12}$ are cooperative cofactors in homocysteine re-methylation to methionine (Selhub et al. 1993; Jacques et al. 2001; Quinlivan et al. 2002; Huerta et al. 2004), whereas serum Se concentrations strongly predict tHcy levels by yet unknown mechanisms (González et al. 2004). We found that higher folate or vitamin $\mathrm{B}_{12}$ levels were not associated with survival time of the cohort, in spite of our previous finding of a strong, inverse linear association between blood folate and tHcy concentrations (Huerta et al. 2004). Therefore, albeit important in diminishing tHcy levels, probably folate would not be effective by itself to a sufficient extent as to achieve low enough

Table 1. Baseline characteristics of the sample according to vital status (Mean values and standard deviations, or percentage of subjects)

\begin{tabular}{|c|c|c|c|c|c|c|c|c|c|c|}
\hline & \multicolumn{2}{|c|}{ All $(n 215)$} & \multicolumn{2}{|c|}{ Men ( $n$ 88) } & \multicolumn{2}{|c|}{ Women ( $n$ 127) } & \multicolumn{2}{|c|}{ Alive $(n 155)$} & \multicolumn{2}{|c|}{ Dead $(n 60)$} \\
\hline & Mean & SD & Mean & SD & Mean & SD & Mean & SD & Mean & SD \\
\hline Female sex (\%) & \multicolumn{2}{|c|}{$59 \cdot 1$} & \multicolumn{2}{|c|}{ - } & \multicolumn{2}{|c|}{ - } & \multicolumn{2}{|c|}{61.9} & \multicolumn{2}{|c|}{$51 \cdot 7$} \\
\hline Age (years) & $75 \cdot 1$ & 6.5 & 73.4 & $7 \cdot 3$ & $76 \cdot 3^{\star}$ & $5 \cdot 7$ & 74.8 & $6 \cdot 8$ & $75 \cdot 9$ & 5.9 \\
\hline $\mathrm{BMI}\left(\mathrm{kg} / \mathrm{m}^{2}\right)$ & $27 \cdot 8$ & 4.9 & $27 \cdot 2$ & 3.9 & $28 \cdot 2$ & 5.5 & $28 \cdot 2$ & 4.8 & $26 \cdot 4 \dagger$ & $5 \cdot 1$ \\
\hline Smoker (\%) & \multicolumn{2}{|c|}{15.0} & \multicolumn{2}{|c|}{31.0} & \multicolumn{2}{|c|}{$3.9^{*}$} & \multicolumn{2}{|c|}{16.9} & \multicolumn{2}{|c|}{$10 \cdot 0$} \\
\hline Plasma homocysteine $(\mu \mathrm{mol} / \mathrm{l})$ & $12 \cdot 9$ & $5 \cdot 1$ & $13 \cdot 0$ & $6 \cdot 0$ & $12 \cdot 8$ & 4.4 & $12 \cdot 4$ & $5 \cdot 0$ & $14 \cdot 1 \dagger$ & $5 \cdot 3$ \\
\hline Serum folate $(\mathrm{nmol} / \mathrm{l})$ & $12 \cdot 6$ & $8 \cdot 7$ & 11.9 & $8 \cdot 7$ & $13 \cdot 1^{\star}$ & $8 \cdot 6$ & $12 \cdot 7$ & 8.4 & 12.5 & $9 \cdot 3$ \\
\hline Serum vitamin $B_{12}(\mathrm{pmol} / \mathrm{l})$ & $299 \cdot 2$ & $163 \cdot 1$ & $297 \cdot 3$ & 163.8 & $300 \cdot 6$ & $163 \cdot 2$ & 294.3 & $156 \cdot 8$ & $312 \cdot 0$ & $179 \cdot 1$ \\
\hline Serum Se $(\mu \mathrm{mol} / \mathrm{l})$ & $1 \cdot 10$ & 0.22 & 1.09 & 0.22 & $1 \cdot 11$ & 0.21 & $1 \cdot 12$ & 0.2 & $1.04 \dagger$ & 0.20 \\
\hline Cognitive scoreł & $26 \cdot 3$ & $5 \cdot 7$ & $27 \cdot 7$ & $5 \cdot 1$ & $25 \cdot 3^{*}$ & 5.9 & $26 \cdot 6$ & $5 \cdot 5$ & $25 \cdot 5$ & 5.9 \\
\hline
\end{tabular}

* Mean value or percentage was significantly different from that of the men $(P<0.05)$.

$\dagger$ Mean value was significantly different from that of the survivors $(P<0.05)$.

$\ddagger$ Mini Mental State Examination score (adapted by Lobo et al. (2005) for the Spanish population). 
Table 2. Estimates of risk derived from Cox proportional hazards models for plasma homocysteine, folate, vitamin $\mathrm{B}_{12}$ and selenium as predictors of survival time

(Relative risks (RR) and $95 \%$ confidence intervals)

\begin{tabular}{|c|c|c|c|c|c|c|}
\hline & \multicolumn{2}{|c|}{ Deaths } & \multirow[b]{2}{*}{$\mathrm{RR} \dagger$} & \multirow[b]{2}{*}{$95 \% \mathrm{Cl}$} & \multirow[b]{2}{*}{$\mathrm{RR} \ddagger$} & \multirow[b]{2}{*}{$95 \% \mathrm{Cl}$} \\
\hline & $n$ & $\%$ & & & & \\
\hline \multicolumn{7}{|c|}{ Plasma homocysteine $(\mu \mathrm{mol} / \mathrm{l})$} \\
\hline$\leq 8.7$ & 10 & 21.7 & 1 & - & 1 & - \\
\hline $8 \cdot 8-10 \cdot 7$ & 11 & $26 \cdot 8$ & 1.203 & $0.506,2.859$ & 1.436 & $0.578,3.571$ \\
\hline $10 \cdot 8-13 \cdot 3$ & 8 & $18 \cdot 6$ & 0.818 & $0.320,2.090$ & 0.914 & $0.331,2.528$ \\
\hline $13 \cdot 4-16 \cdot 6$ & 11 & $25 \cdot 6$ & 1.018 & $0.431,2.406$ & $1 \cdot 212$ & $0.487,3.014$ \\
\hline$>16 \cdot 7$ & $20 \ddagger$ & $47 \cdot 6$ & $2 \cdot 012$ & $0.937,4.317$ & $2 \cdot 297^{\star}$ & $1.021,5.169$ \\
\hline Trend $(P)$ & & & & 0.105 & & 0.075 \\
\hline \multicolumn{7}{|c|}{ Serum folate $(\mathrm{nmol} / \mathrm{l})$} \\
\hline$\leq 7.5$ & 14 & 32.6 & 1 & - & 1 & - \\
\hline $7 \cdot 6-8.9$ & 13 & $31 \cdot 0$ & 0.831 & $0.388,1.781$ & 0.936 & $0.404,2 \cdot 167$ \\
\hline $9.0-10.9$ & 13 & $30 \cdot 2$ & 0.888 & $0.413,1.906$ & 0.990 & $0.433,2.265$ \\
\hline $11 \cdot 0-15 \cdot 1$ & 9 & $20 \cdot 5$ & 0.588 & $0.251,1.381$ & 0.730 & $0.297,1.793$ \\
\hline$>15 \cdot 2$ & 11 & $25 \cdot 6$ & 0.690 & $0.310,1.535$ & 0.936 & $0.400,2 \cdot 188$ \\
\hline Trend $(P)$ & & & & 0.258 & & 0.725 \\
\hline \multicolumn{7}{|c|}{ Serum vitamin $B_{12}(\mathrm{pmol} / \mathrm{l})$} \\
\hline$\leq 201.4$ & 10 & $22 \cdot 2$ & 1 & - & 1 & - \\
\hline $201.5-239.0$ & 10 & 24.4 & 1.055 & $0.435,2.559$ & 1.000 & $0.399,2.504$ \\
\hline $239 \cdot 1-286 \cdot 0$ & 12 & $27 \cdot 9$ & 1.388 & $0.599,3.217$ & 1.107 & $0.456,2.685$ \\
\hline $286 \cdot 1-362 \cdot 0$ & 14 & $32 \cdot 6$ & 1.775 & $0.783,4.022$ & $1 \cdot 810$ & $0.783,4.183$ \\
\hline$>362.1$ & 14 & 32.6 & 1.703 & $0.752,3.858$ & 1.990 & $0.866,4.569$ \\
\hline Trend $(P)$ & & & & 0.091 & & 0.043 \\
\hline \multicolumn{7}{|c|}{ Serum Se $(\mu \mathrm{mol} / \mathrm{l})$} \\
\hline$\leq 0.92$ & 17 & $36 \cdot 2$ & 1 & - & 1 & - \\
\hline $0.93-1.04$ & 14 & $37 \cdot \overline{8}$ & 0.940 & $0.461,1.916$ & 1.133 & $0.536,2.395$ \\
\hline $1.05-1.14$ & 10 & $22 \cdot 2$ & 0.665 & $0.302,1.465$ & 0.686 & $0.294,1.603$ \\
\hline $1.15-1.25$ & 11 & $25 \cdot 6$ & 0.692 & $0.323,1.486$ & 0.813 & $0.364,1.816$ \\
\hline$>1.26$ & 8 & $18 \cdot 6$ & 0.647 & $0.278,1.508$ & 0.565 & $0.228,1.404$ \\
\hline Trend $(P)$ & & & & 0.191 & & 0.158 \\
\hline
\end{tabular}

*Increased risk of death was significant $(P<0.05)$.

$\dagger$ Adjusted for age and sex.

$\ddagger$ Adjusted for age, sex, smoking habit, BMI and cognitive score.

tHcy concentrations to prevent overall mortality in the cohort. Regarding vitamin $\mathrm{B}_{12}$ levels, while it is common that elderly subjects could be at risk of cobalamin deficiency, less than $15 \%$ of subjects in our cohort had suboptimal serum concentrations (below $185 \mathrm{pmol} / \mathrm{l}$ ) (Selhub et al. 1999). Because of these high levels of vitamin $\mathrm{B}_{12}$ we were unable to find a linear association between serum cobalamin and tHcy in a previous report (Huerta et al. 2004). The present results are not conclusive in regard to the association of cobalamin with survival time. While we found a significant direct trend, the categorical analysis did not support an association between cobalamin and overall survival. Further research is required to help clarify this topic.

Our group has recently found that Se is inversely associated with tHcy in human subjects (González et al. 2004), but the present results do not clearly support an overall protective effect in regard to mortality. In the present study, the percentage of deaths did not significantly differ across quintiles of serum Se. Se did not significantly predict survival time in Cox models, either. Although it is generally assumed that a poor Se status has an adverse impact on health maintenance and proper function of body systems (Rayman, 2000), epidemiological evidence on the role of $\mathrm{Se}$ on survival remain inconclusive. Cardiovascular mortality was not affected by Se status in case-control studies or after long-term supplementation (Salonen et al. 1985; Kok et al. 1987b; Stranges et al. 2006), except for those with low basal Se status (Salonen et al. 1982). On the other hand, previous evidence showed that cancer-related mortality was higher in elderly subjects with lower basal Se concentrations (Akbaraly et al. 2005) and that daily supplementation with $200 \mu \mathrm{g}$ Se reduced cancer incidence and mortality in adult populations (Kok et al. 1987a; Duffield-Lillico et al. 2002), but the effect generally seems to be restricted to men and to subjects in the lowest categories of basal Se levels (although the consideration of 'low Se level' largely differs among these studies). This sexspecific effect led us to check for potential differences in total mortality risk by sex across levels of serum Se. We found that women, but not men, in the highest quintile of serum Se distribution had up to $83 \%$ lower chance of overall death (women: odds ratio 0.168 (95\% CI $0.032,0.873$ ), $P=0.034$; men: odds ratio 0.978 (95\% CI 0.310, 3.083), $P=0.970$; data not shown). This association persisted after including tHcy as a predictor in the adjusted model, which suggests that the protective effect of Se would not entirely rely on its association with homocysteine. Se has many other important functions: it is a cofactor of glutathione peroxidase protecting against harmful peroxidation (Heyland et al. 2005); it modulates the response to oxidative stress by inducing a faster restoration of the endogenous antioxidant defence system (Savarino et al. 2001); besides, Se plays an important role in immunity, thyroid function and inflammatory 
processes, among other actions, that would partly account for its direct association with survival time in human subjects (Rayman, 2000). The fact that this effect has been found to be restricted to either men or women, depending on the study, raises the question of whether there exist unknown sex-related factors underlying the association of serum Se with mortality.

In interpreting these results, some considerations should be borne in mind. The study suffers from a low sample size that may have resulted in a reduced statistical power. But, on the other hand, the finding of significant differences in spite of this limited statistical power allows us to feel confident about the results that we did find. Because of the low number of subjects and, subsequently, of deaths (sixty cases), further larger population-based studies should estimate the magnitude of these associations with greater accuracy. Also, the present study has been carried out in an institutionalised population, and it is not clear to what extent these results can be generalised to free-living elderly. Finally, a longer follow-up period will show whether tHcy also predicts survival time on a long-term basis.

To our knowledge, the present study is the first prospective epidemiological study in the literature that examines the association on survival time of blood levels of homocysteine, folate, cobalamin and Se together, in non-patient elderly not receiving micronutrient supplementation. According to our data, physiological concentrations of tHcy were predictive of risk of overall mortality, while folate and vitamin $B_{12}$ levels were not. Higher serum Se showed a beneficial effect, although only in women. The role of tHcy in predicting risk of death merits further research efforts.

\section{Acknowledgements}

We thank the staff of the elderly care institutions for their participation in the present study. The present study was supported by a grant from ERA (Establecimientos Residenciales para Ancianos Asturianos), a grant FIS-02-PI020141 from the Spanish Fondo de Investigaciones Sanitarias (Instituto de Salud Carlos III, Madrid, Spain), and a Grande Covián grant from the Prince of Asturias Foundation (Oviedo, Spain).

\section{References}

Akbaraly NT, Arnaud J, Hininger-Favier I, Gourlet V, Roussel AM \& Berr C (2005) Selenium and mortality in the elderly: Results from the EVA Study. Clin Chem 51, 2117-2123.

Anderson JL, Muhlestein JB, Horne BD, Carlquist JF, Bair TL, Madsen TE \& Pearson RR (2000) Plasma homocysteine predicts mortality independently of traditional risk factors and C-reactive protein in patients with angiographically defined coronary artery disease. Circulation 102, 1227-1232.

Araki A \& Sako Y (1987) Determination of free and total homocysteine in human plasma by high-performance liquid chromatography with fluorescence detection. J Chromatogr 422, 43-52.

Bonaa KH, Njolstad I, Ueland PM, Schirmer H, Tverdal A, Steigen T, Wang H, Nordrehaug JE, Arnesen E \& Rasmussen K (2006) Homocysteine lowering and cardiovascular events after acute myocardial infarction. $N$ Engl J Med 354, 1578-1588.

Bostom AG, Silbershatz H, Rosenberg IH, Selhub J, D'Agostino RB, Wolf PA, Jacques PF \& Wilson PW (1999) Nonfasting plasma total homocysteine levels and all-cause and cardiovascular disease mortality in elderly Framingham men and women. Arch Intern Med 159, 1077-1080.

Boushey CJ, Beresford SA, Omenn GS \& Motulsky AG (1995) A quantitative assessment of plasma homocysteine as a risk factor for vascular disease. Probable benefits of increasing folic acid intakes. JAMA 274, 1049-1057.

Brouwer IA, Verhoef P \& Urgert R (2000) Betaine supplementation and plasma homocysteine in healthy volunteers. Arch Intern Med 160, 2546-2547.

Buccianti G, Baragetti I, Bamonti F, Furiani S, Dorighet V \& Patrosso C (2004) Plasma homocysteine levels and cardiovascular mortality in patients with end-stage renal disease. J Nephrol 17, 405-410.

Clarke R, Smith AD, Jobst KA, Refsum H, Sutton L \& Ueland PM (1998) Folate, vitamin $B_{12}$, and serum total homocysteine levels in confirmed Alzheimer disease. Arch Neurol 55, 1449-1455.

de Bree A, Verschuren WM, Blom HJ, Nadeau M, Trijbels FJ \& Kromhout D (2003) Coronary heart disease mortality, plasma homocysteine, and B-vitamins: a prospective study. Atherosclerosis 166, 369-377.

Duffield-Lillico AJ, Reid ME, Turnbull BW, Combs GF Jr, Slate EH, Fischbach LA, Marshall JR \& Clark LC (2002) Baseline characteristics and the effect of selenium supplementation on cancer incidence in a randomized clinical trial: a summary report of the Nutritional Prevention of Cancer Trial. Cancer Epidemiol Biomarkers Prev 11, 630-639.

Egerton W, Silberberg J, Crooks R, Ray C, Xie L \& Dudman N (1996) Serial measures of plasma homocyst(e)ine after acute myocardial infarction. Am J Cardiol 77, 759-761.

Finkelstein JD (1990) Methionine metabolism in mammals. J Nutr Biochem 1, 228-237.

González S, Huerta JM, Álvarez-Uría J, Fernández S, Patterson AM \& Lasheras C (2004) Serum selenium is associated with plasma homocysteine concentrations in elderly humans. J Nutr 134, 1736-1740.

Graham IM, Daly LE, Refsum HM, et al. (1997) Plasma homocysteine as a risk factor for vascular disease. The European Concerted Action Project. JAMA 277, 1775-1781.

Hankey GJ \& Eikelboom JW (1999) Homocysteine and vascular disease. Lancet 354, 407-413.

Heyland DK, Dhaliwal R, Suchner U \& Berger MM (2005) Antioxidant nutrients: a systematic review of trace elements and vitamins in the critically ill patient. Intensive Care Med 31, $327-337$.

Homocysteine Studies Collaboration (2002) Homocysteine and risk of ischemic heart disease and stroke: a meta-analysis. JAMA $\mathbf{2 8 8}$, 2015-2022.

Huerta JM, González S, Vigil E, Prada M, San Martín J, Fernández S, Patterson AM \& Lasheras C (2004) Folate and cobalamin synergistically decrease the risk of high plasma homocysteine in a nonsupplemented elderly institutionalized population. Clin Biochem 37, 904-910.

Jacobson BE \& Lockitch G (1988) Direct determination of selenium in serum by graphite-furnace atomic absorption spectrometry with deuterium background correction and a reduced palladium modifier: age-specific reference ranges. Clin Chem 34, 709-714.

Jacques PF, Bostom AG, Wilson PW, Rich S, Rosenberg IH \& Selhub J (2001) Determinants of plasma total homocysteine concentration in the Framingham Offspring cohort. Am J Clin Nutr 73, 613-621.

Jacques PF, Kalmbach R, Bagley PJ, Russo GT, Rogers G, Wilson PW, Rosenberg IH \& Selhub J (2002) The relationship between riboflavin and plasma total homocysteine in the Framingham Offspring cohort is influenced by folate status and the C677T transition in the methylenetetrahydrofolate reductase gene. $J$ Nutr 132, 283-288. 
Kark JD, Selhub J, Adler B, Gofin J, Abramson JH, Friedman G \& Rosenberg IH (1999) Nonfasting plasma total homocysteine level and mortality in middle-aged and elderly men and women in Jerusalem. Ann Intern Med 131, 321-330.

Kasiske BL \& Keane WF (1996) Laboratory assessment of renal disease clearance, urinalysis and renal biopsy. In The Kidney, pp. 1137-1173 [BM Brenner and FC RectorJr, editors]. Philadelphia: WB Saunders.

Kok FJ, de Bruijn AM, Hofman A, Vermeeren R \& Valkenburg HA (1987a) Is serum selenium a risk factor for cancer in men only? Am J Epidemiol 125, 12-16.

Kok FJ, de Bruijn AM, Vermeeren R, Hofman A, van Laar A, de Bruin M, Hermus RJ \& Valkenburg HA (1987b\) Serum selenium, vitamin antioxidants, and cardiovascular mortality: a 9-year follow-up study in the Netherlands. Am J Clin Nutr 45, 462-468.

Lasheras C, González S, Huerta JM, Lombardía C, Ibáñez R, Patterson AM \& Fernández S (2003) Food habits are associated with lipid peroxidation in an elderly population. $J$ Am Diet Assoc 103, $1480-1487$.

Lindgren A, Brattstrom L, Norrving B, Hultberg B, Andersson A \& Johansson BB (1995) Plasma homocysteine in the acute and convalescent phases after stroke. Stroke 26, 795-800.

Lobo A, Saz P \& Marco C (2005) Demencias. In Medición Clínica en Psiquiatría y Psicología, pp. 335-347 [A Bulbena, GE Berrios and P Fernández de Larrinoa, editors]. Barcelona: Masson.

Lonn E, Yusuf S, Arnold MJ, Sheridan P, Pogue J, Micks M, McQueen MJ, Probstfield J, Fodor G, Held C \& Genest J Jr (2006) Homocysteine lowering with folic acid and B vitamins in vascular disease. $N$ Engl J Med 354, 1567-1577.

Morris MS (2003) Homocysteine and Alzheimer's disease. Lancet Neurol 2, 425-428.

Nygard O, Nordrehaug JE, Refsum H, Ueland PM, Farstad M \& Vollset SE (1997) Plasma homocysteine levels and mortality in patients with coronary artery disease. $N$ Engl J Med 337, 230-236.

Omland T, Samuelsson A, Hartford M, Herlitz J, Karlsson T, Christensen B \& Caidahl K (2000) Serum homocysteine concentration as an indicator of survival in patients with acute coronary syndromes. Arch Intern Med 160, 1834-1840.

Perry IJ, Refsum H, Morris RW, Ebrahim SB, Ueland PM \& Shaper AG (1995) Prospective study of serum total homocysteine concentration and risk of stroke in middle-aged British men. Lancet 346, $1395-1398$.

Quinlivan EP, McPartlin J, McNulty H, Ward M, Strain JJ, Weir DG \& Scott JM (2002) Importance of both folic acid and vitamin $B_{12}$ in reduction of risk of vascular disease. Lancet 359, 227-228.

Rayman MP (2000) The importance of selenium to human health. Lancet 356, 233-241.
Rossi GP, Maiolino G, Seccia TM, Burlina A, Zavattiero S, Cesari M, Sticchi D, Pedon L, Zanchetta M \& Pessina AC (2006) Hyperhomocysteinemia predicts total and cardiovascular mortality in high-risk women. J Hypertens 24, 851-859.

Salonen JT, Alfthan G, Huttunen JK, Pikkarainen J \& Puska P (1982) Association between cardiovascular death and myocardial infarction and serum selenium in a matched-pair longitudinal study. Lancet ii, 175-179.

Salonen JT, Salonen R, Penttila I, Herranen J, Jauhiainen M, Kantola M, Lappetelainen R, Maenpaa PH, Alfthan G \& Puska P (1985) Serum fatty acids, apolipoproteins, selenium and vitamin antioxidants and the risk of death from coronary artery disease. Am J Cardiol 56, 226-231.

Savarino L, Granchi D, Ciapetti G, Cenni E, Ravaglia G, Forti P, Maioli F \& Mattioli R (2001) Serum concentrations of zinc and selenium in elderly people: results in healthy nonagenarians/centenarians. Exp Gerontol 36, 327-339.

Saw SM, Yuan JM, Ong CN, Arakawa K, Lee HP, Coetzee GA \& Yu MC (2001) Genetic, dietary, and other lifestyle determinants of plasma homocysteine concentrations in middle-aged and older Chinese men and women in Singapore. Am J Clin Nutr 73, 232-239.

Selhub J (1999) Homocysteine metabolism. Annu Rev Nutr 19, $217-246$.

Selhub J, Jacques PF, Rosenberg IH, Rogers G, Bowman BA, Gunter EW, Wright JD \& Johnson CL (1999) Serum total homocysteine concentrations in the third National Health and Nutrition Examination Survey (1991-1994): population reference ranges and contribution of vitamin status to high serum concentrations. Ann Intern Med 131, 331-339.

Selhub J, Jacques PF, Wilson PW, Rush D \& Rosenberg IH (1993) Vitamin status and intake as primary determinants of homocysteinemia in an elderly population. JAMA 270, 2693-2698.

Stehouwer CD, Gall MA, Hougaard P, Jakobs C \& Parving HH (1999) Plasma homocysteine concentration predicts mortality in non-insulin-dependent diabetic patients with and without albuminuria. Kidney Int 55, 308-314.

Stranges S, Marshall JR, Trevisan M, Natarajan R, Donahue RP, Combs GF, Farinaro E, Clark LC \& Reid ME (2006) Effects of selenium supplementation on cardiovascular disease incidence and mortality: secondary analyses in a randomized clinical trial. Am J Epidemiol 163, 694-699.

Verhoef P \& de Groot LC (2005) Dietary determinants of plasma homocysteine concentrations. Semin Vasc Med 5, 110-123.

Vollset SE, Refsum H, Tverdal A, Nygard O, Nordrehaug JE, Tell GS \& Ueland PM (2001) Plasma total homocysteine and cardiovascular and noncardiovascular mortality: the Hordaland Homocysteine Study. Am J Clin Nutr 74, 130-136. 